\title{
Meat Prices
}

The price of food remains a topic of much concern to consumers, Government officials, and the food industry. In the past six months food prices have increased at an exceptional 20 per. cent annual rate. Since meat purchases represent a substantial portion of constumer expenditures on food, it seems reasonable that meat price increases would receive more attention than price increases for other items. The persistence of this situation has prompted publication of the following abridged and updated version of an article which appeared in the October 1972 issue of this Review.

One can only distribute and consume what has been produced, this is an elementary truth. ${ }^{1}$

The sharp increases in retail meat prices in recent months have been the subject of much discussion. The increases have had a major impact on total consumer outlays since meat expenditures account for about onethird of the average family food budget. Reflecting their disappointment at these higher costs, some people have accused farmers, meat packers, and grocery stores of "gouging consumers" by forcing meat prices up. These views are generally stated without a full understanding of the underlying economic processes involved in price determination.

This note presents an economic analysis of the forces which have led to meat price increases. The analysis emphasizes the function of the market system in pricing meat, in allocating meat products to consumers, and in allocating resomces to meat production.

\section{FCONOMO ANALYSS OH PMCL DETTIIIINATION}

An economic approach to determining prices of meat or any other commodity holds that changes in meat prices at grocery stores result from a series of market factors rather than arbitrary decisions by farmers, meat packers, wholesalers, and retailers. Behind retail price increases is often found greater consumer demand as indicated by a rising volume of sales. When the demand for a commodity increases, the first change one typically observes is a higher sales volume which results initially in a reduction of inventories. In order to restore depleted inventories re-

Leonid I. Brezlnev, First Secretary of the Soviet Communist Party (New York Times, May 29, 1971).

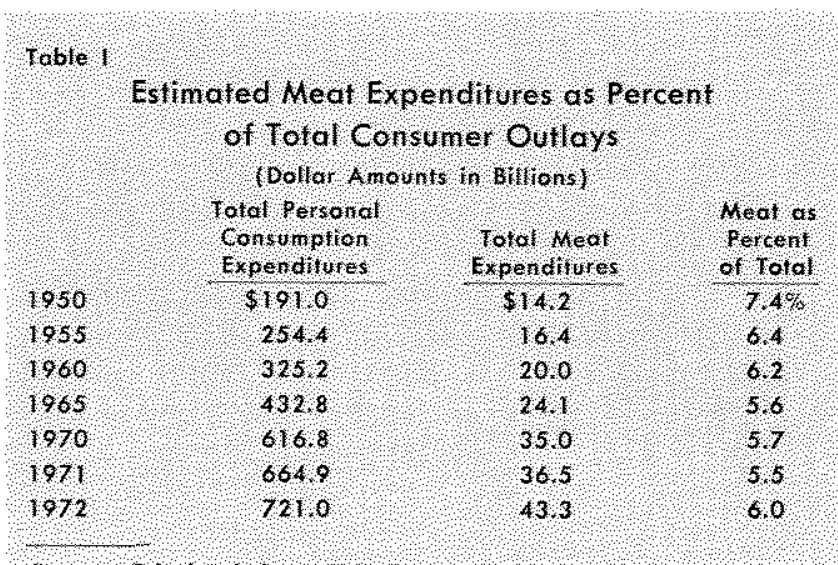

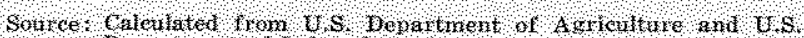
Departrint of labon data

tail grocers increase their meat orders from packers hoping to continue selling a larger volume at the prevailing price. Upon receiving increased orders for meat the packers in turn increase their rate of meat slaughter and seek to restore meat animal inventories by additional purchases from farmers. Since the prevailing price only provides sufficient incentive for producing the current number of animals, additional animals are not available for immediate delivery at current prices. As packers compete among themselves in an attempt to obtain more animals, they raise their offering prices to farmers. ${ }^{2}$

In the short run the number of animals available for marketing is relatively fixed. The number of animals on farms cannot be increased rapidly and the increase in meat production per animal is relatively limited.

-See Armen A. Alchian and William R. Allen, University Economics, 3rd ed. (Belmont, Californa: Wadsworth Publishing Company, Ine, 1972), pp. 95-97. 


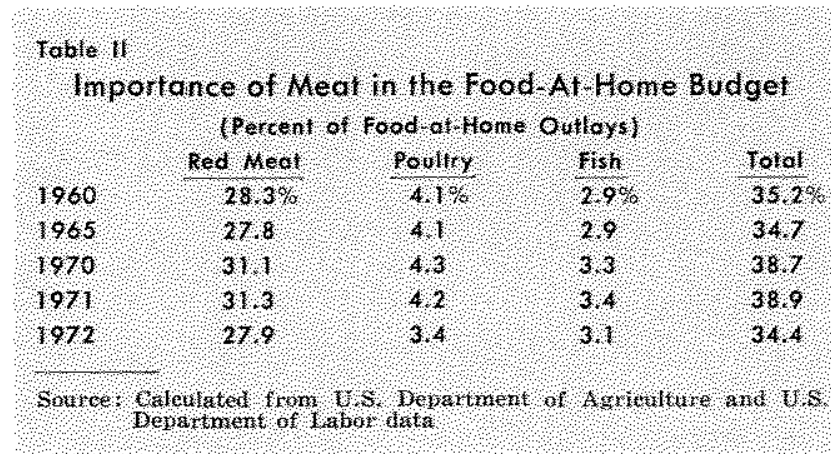

In other words, the supply of meat is "inelastic" with respect to price in the short run; only a small percent increase in quantity will be forthcoming with a relatively large percent increase in price.

Over the longer run, however, the supply of meat is more "elastic," meaning that with each incremental increase in price, a larger quantity will be offered than in the short run. Given sufficient time, farmers and ranchers find it profitable to expand their meat animal breeding herds and produce additional animals for slaughter. The fact that the long-run meat supply is more elastic than the short-run supply means that a given increase in demand for meat has a smaller impact on prices after passage of some time. Nevertheless, any increase in the demand for meat involves a rise in the price paid by consumers. The higher price equates the larger amount demanded with the amount supplied.

Conversely, declines in meat demand, or advancements in production technology which tend to increase supply, result in lower prices. More meat animals are offered to packers and more meat to consumers than can be sold at previous prices. Prices are thus marked down by retail grocers until the quantity of meat demanded by consumers equals the amount supplied.

\section{DEMAND FOR MPAT IIAS INCWEASED}

Demand for meat has increased substantially in recent years, as evidenced by the fact that consumers have purchased larger quantities of meat at higher prices. Factors contributing to the greater demand include rising per capita incomes, increased food subsidy programs, and a larger population.

\section{Bon Consumplion and prices lave When}

During the period of rapid increase in average meat prices from 1964 to 1972 , total meat consumed rose from 42 to 52 billion pounds. Per capita consumption rose from 224 to 253 pounds. The rise in per capita consumption was at a faster rate during this period of rapid price increase than during the previous 14 years (1950-64) when prices were relatively stable.

The fact that meat consumption has increased reveals little about meat demand without information on prices. ${ }^{3}$ Meat consumption, like consumption of any other commodity or service, depends in part upon its price. Given no change in the demand, a decline in meat prices will induce consumers to purchase a larger quantity. For example, a larger volume of meat production caused by livestock cycles or by unusually favorable weather conditions will increase the supply and result in lower prices. The lower prices will induce some consumers to purchase larger quantities of meat. Conversely, a cyclical or seasonal decline in meat output will cause an increase in meat prices, which will in turn cause some consumers to substitute other types of food for meat and reduce their meat purchases. These short-run changes in supply can cause price changes without a change in demand. Such short-run changes in supply have no doubt been a factor in the irregular upward course of meat prices since 1964. However, consumers have purchased larger quantities of meat at higher prices per pound indicating that demand has increased.

\section{Food Stubides Have Increasol}

Larger Government issues of food stamps to the lower income groups and increased donations of meat products to schools, institutions, and low-income families occurred during the recent upswing in meat prices. Total issues of food stamps rose from $\$ 0.7$ billion in 1969 to $\$ 3.6$ billion in 1972 . Federal outlays on the school lunch program have more than tripled during the last three years, rising from $\$ 227$ million in 1969 to $\$ 788$ million in 1972. Food distributions to low-income families, institutions, and others also have increased, but at a lower rate than the school lunch programs. Total Government outlays for the Federal food programs, including food stamps, food distribution, and money donated for food purchases, rose from $\$ 1.2$ billion in 1969 to $\$ 3.5$ billion in 1972. In 1969 Government outlays for these programs amounted to only 1.4 percent of the total costs of food used at home by all consumers. By 1972 these outlays amounted to more than 3.6 percent of total food-at-home costs.

\footnotetext{
3Economists explain a larger quantity of a good being parchased in two different wiys. One way is for the demand schedule to shift to the right, indicating a greater atuantity will be taken at each price. The other way is a movement along a given demand schedule, indicating that price changes are the result of a shift in the supply schedule. The latter means that larger quantities are purchased only at lower prices. Both schedules may also shift simultaneously.
} 


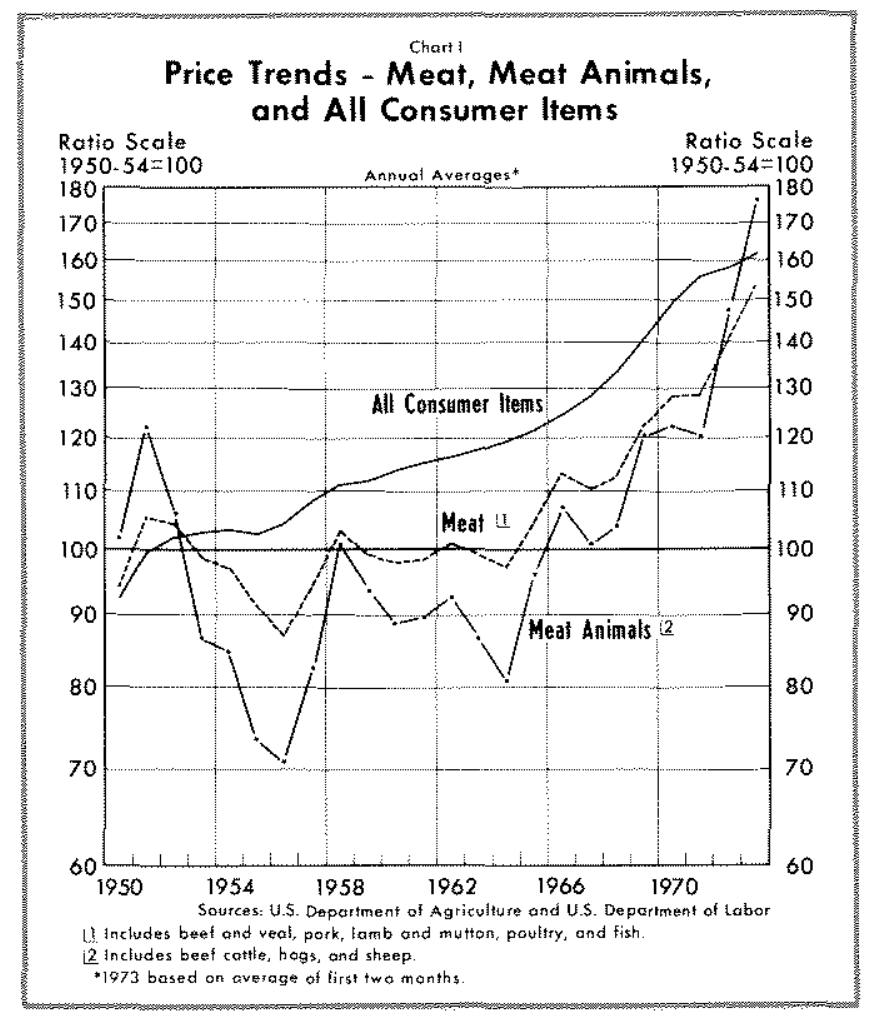

MUAT SUPPIY

Over the longer run, production technology and imports have tended to increase the nation's meat supply and offset part of the impact on prices of the rising demand for meat. As shown in Charts I and II, meat production plus net imports have risen at a sufficient rate to provide consumers with increasing quantities at less than average price increases for other consumer items. From 1950 to 1972 , red meat and poultry production combined rose from 25.9 to 48.1 billion pounds, a 3 percent annual rate of gain. Production of red meat rose from 22.1 to 37 billion pounds, an annual rate of 2.4 percent, while output of chickens almost tripled. Meat imports in 1972 were equivalent to 6 percent of domestic red meat production, whereas imports were insignificant in 1950 . Meat import controls were relaxed last year, and if they are not reimposed, rising meat production in other nations, along with rising domestic meat production efficiency, should have an even more favorable impact on the nation's meat supply in future years.

Between 1950 and 1972, when meat consumption was increasing rapidly, prices of meat animals rose 1.7 percent per year, and red meat prices rose 2.1 percent per year. Broiler prices declined 1.6 percent per year. In comparison, the consumer and general price indexes rose at average annual rates of 2.7 and 2.9 percent, respectively.

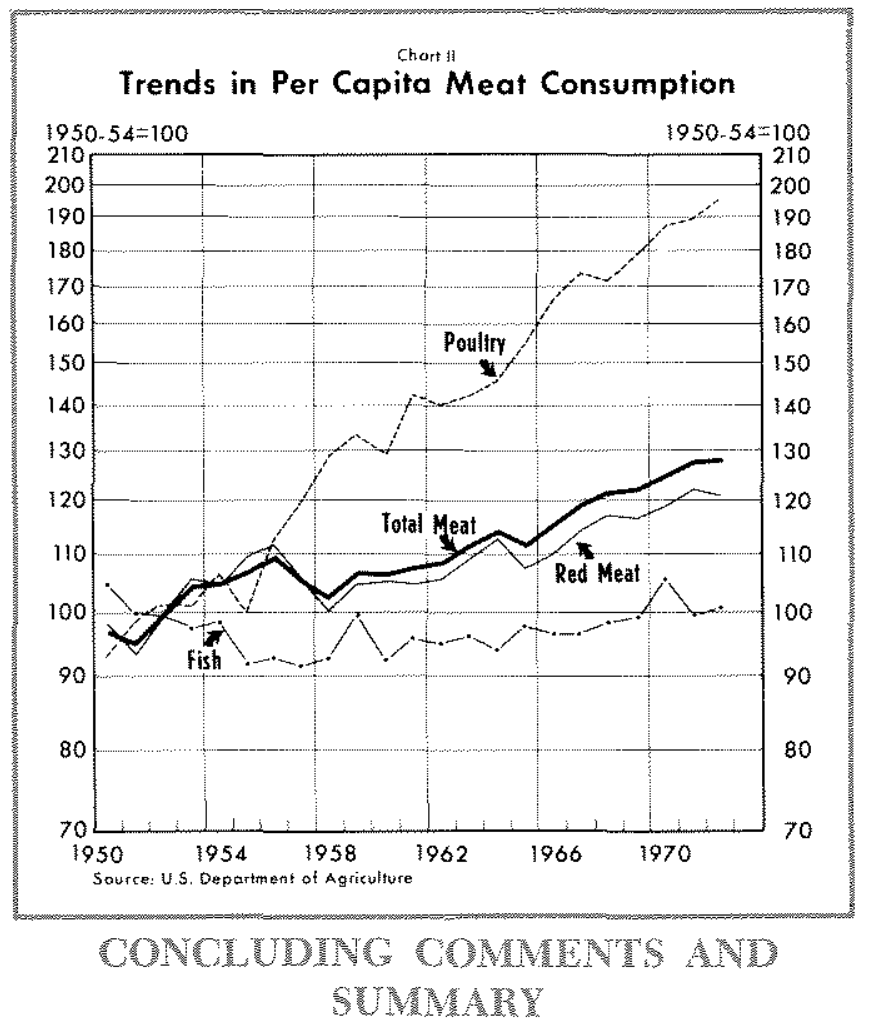

The data indicate that meat prices in recent years have been determined largely by basic supply and demand conditions. With the exception of the Government crop control and price support programs and import restrictions, the meat industry has generally operated in a competitive, free enterprise atmosphere.

The meat industry meets a major competitive test of easy entry and exit. The industry is not hampered by rules and regulations such as chartering, licensing, or long periods of apprenticeship. Virtually all are free to enter all phases of meat production and distribution. It has numerous participants in all stages of production and distribution. The efficient prosper and the inefficient fail. This incentive has permitted the price mechanism to bring into equality the quantity of meat supplied and demanded at a relatively high level of consumption per capita and at prices which have risen only moderately compared with other consumer items.

If people want more meat they will bid up the price and the higher prices of meat will provide the incentive for increased production. Productive resources will flow freely to this sector when anticipated returns are attractive. The higher meat prices in recent years have been necessary to attract the additional resources used in producing the larger volume of meat demanded by consumers. If prices had been 
set arbitrarily at a lower level, a smaller volume would have been produced and some consumers would have had less meat. Therefore, in the absence of a responsive price system in which the quantity supplied and the quantity demanded are equated, the available quantity must be rationed anong consumers by some other means.

In summation, the fact that meat prices have increased sharply in the past year, and have generally risen since 1964, is not a sufficient reason for the belief that the consumer is being taken advantage of or that the meat industry is callous or inefficient. The meat industry is reasonably competitive and takes advan. tage of developing technology. Meat production has increased at a high rate since the upward trend in meat prices began in 1964. Consumers have demanded a higher level of meat production per capita, and have paid a higher price for the increased output.

The higher prices were necessary to provide incentive for producers to supply the amount of meat demanded. Without the higher prices output would have been less. Unforeseen events such as livestock cycles and unusual weather conditions may cause livestock and meat prices to fluctuate around their long-run equilibrium levels. However, given the generally competitive conditions in the industry, the market price of meat is always near that level required to match production with consumer demand. The recent price increases were probably no exception to this general rule.

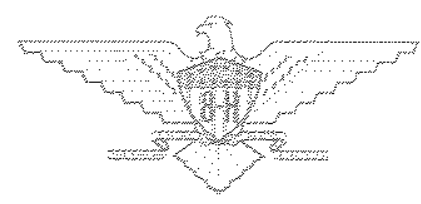

